Original Article

\title{
AN EXPLORATORY ANALYSIS OF MARKETING-MIX IMPACT ON SUPPLY CHANNELS USED BY COMMUNITY PHARMACISTS ENGAGED IN HEALTHCARE SERVICES IN NIGERIA
}

\author{
THEOPHILUS EHIDIAMEN OAMEN ${ }^{1}$ OAMEN SOPHIA OMORENUWA²
}

1Department of Clinical Pharmacy and Pharmacy Administration, Faculty of Pharmacy, Obafemi Awolowo University, Osun State, Nigeria, 2Department of Clinical Pharmacy and Pharmacy Administration, Faculty of Pharmacy, University of Ibadan, Oyo State, Nigeria

Email: oamentheo@yahoo.com

Received: 16 Jun 2021, Revised and Accepted: 17 Aug 2021

ABSTRACT

Objective: The main objective of this study was to evaluate the influence of marketing-mix concepts on the purchasing engagements of community pharmacists with supply channels in low and middle-income settings. Secondly, to use an Impact scale to measure the dominant marketing-mix factors that influence procurement decision-making practices.

Methods: A descriptive study that used self-administered questionnaires, distributed to community pharmacists from March to May 2021 in Southwestern, Nigeria. A mixed-method sampling technique was adopted. Ethical approval was given by the Ministry of health (HPRS/381/371). Study outcomes were compared against measures of the Impact scale. Descriptive and Inferential statistics were used to test the study hypotheses using SPSS-25. Significance was set at $\mathrm{p}<0.05$

Results: The response rate was $79.6 \%$ representing 398 community pharmacists. Age of community pharmacists had significant association with price-sensitivity $(\mathrm{p}<0.01)$. Community pharmacists with more employees tended to be price-sensitive $(\mathrm{p}=0.003)$. Promotion variable had the highest influence (Mean score $=2.73, \mathrm{SD}=0.43$, Impact-level=moderate), followed by Price (Mean score $=2.65, \mathrm{SD}=0.34$, Impact-level=moderate), Place (Mean score $=2.61, \mathrm{SD}=0.51$, Impact-level=moderate), Perception (Mean score $=2.48, \mathrm{SD}=0.42$, Impact-level=low), and the least impactful was Product (Mean score $=2.46, \mathrm{SD}=0.41$, Impact level=low). The study revealed an overall low-to-moderate involvement $(\mathrm{Mean}$ score $=2.59, \mathrm{SD}=0.42)$ and influence of marketing-mix on the level of engagement of community pharmacists with supply channels.

Conclusion: Findings suggest a shift of focus away from product-based considerations. Therefore, the study recommends a more balanced decision approach using an Impact rating scale. Improved focus on key priorities that can positively impact quality pharmaceutical care to the patient is advocated.

Keywords: Pharmacy practice, Community pharmacists, Marketing-mix, Purchasing, Decision-making, Impact, low and middle-income countries, Outcome Research, Healthcare services, Nigeria

(C) 2021 The Authors. Published by Innovare Academic Sciences Pvt Ltd. This is an open access article under the CC BY license (https://creativecommons.org/licenses/by/4.0/) DOI: https://dx.doi.org/10.22159/ijpps.2021v13i10.42447. Journal homepage: https://innovareacademics.in/journals/index.php/ijpps.

\section{INTRODUCTION}

Globally, the mechanisms involved in managing drug supply channels are central to the seamless management of a community pharmacy practice. Community pharmacists (CPs) are entrusted with the task of ensuring the supply and dispensing of recommended medicines as required by the patient. This value chain is characterized by the interplay of relationships between the patient, community pharmacist, and suppliers. The ideals of pharmaceutical care demand that this chain should be properly and efficiently managed to guarantee the availability of safe, efficacious, and affordable medicines for the patient [1, 2]. There is limited literature about the role and influence of marketing-mix on the purchase decisions of community pharmacists in practice settings. In low and middle-income countries, the role of marketing concepts in community pharmacy practice is yet to be explored. At the core of the marketing process, there are four typical elements-Product, Price, Promotion, and Place, all geared towards meeting the needs of the customer [3-6]. Price refers to the cost component; it encompasses how much is paid for the procurement of medicines. It also includes the cost of transportation of inventory from the supplier to the pharmacy, credit management and control, price negotiations, cost of business, cost of the product itself. Price is largely dependent on the capacity of the Community pharmacist to procure medicines with the associated costs [7] The chaotic drug distribution system and foreign exchange challenges in low and middle-income countries coupled with a barely existent social welfare system, negatively result in the escalation of cost to the patient and high drug acquisition costs to the community pharmacist with an attendant negative impact on profit margins. The overall impact of pricing on the value chain is that it influences how much the product will cost the patient [8-10]. In general terms, Product in the context of pharmaceutical sales and marketing refers to the pharmaceutical medicine or non-medicinal entities and their associated attributes used for the treatment needs of the patient [11].

Associated aspects of Product are; product range, category or therapeutic group (prescription, and non-prescription drugs), product information needs, management of product quality concerns. The specific attributes and characteristics of the Product variable are dependent on the medication needs of the patient and the requirement of the CPs in terms of inventory needs [12]. The variable Place refers to the channels, avenues, and medium through which pharmaceutical products are made available, accessible on time to the $\mathrm{CP}$ with the patient as the focal point. It typically refers to how the supply chain mechanism delivers the product from the marketer or manufacturer to the final consumer [13-15]. The key elements of the place include distribution channel, access concerns, the proximity of location, ease of transportation, and logistics management [7]. Promotion refers to the set of activities targeted at improving the level and volume of the transaction between the supplier and the CP. These activities include awareness campaigns, prescription-generation from pharmaceutical companies, contractual agreements, discount offers on products, volume-based, and value-based discounts [16] The fifth element included in this study is Perception of value, albeit the presence of the typical 4P's of marketing, the researchers explored the context of Perception to refer to how CPs perceive the entirety of offering from the channels they procure from per time. Perception elements include satisfaction with service quality, process flow, utility value, ease of business transaction, and administration [5, 11]. Furthermore, for a community pharmacy practice to be competitive, it should be able to maximally utilize (effective blend) the various elements of the 
marketing mix, to arrive at an effective procurement decision. In a developing country like Nigeria, CPs daily take such decisions mainly from three main supply channels; pharmaceutical manufacturers or their licensed distributors, local wholesalers, and mega distributors from open drug markets $[9,10,17]$. The relevance of this study is that it further improves CPs' understanding of the procurement process within the frame of the influence of marketing-mix concepts. In other words, the uniqueness of this is that it highlights the influence of the marketing mix from the perspective of the CPs.

To the best of our knowledge, the influence of marketing mix concepts on the purchasing engagements of community pharmacists with supply channels in Nigeria has not been studied or evaluated.

The main objective of the study is to explore the impact of the marketing mix on supply channel engagement by community pharmacists in Nigeria. Secondly, to use an Impact rating scale to measure the dominant marketing-mix factors that influence procurement decision-making practices in low and middle-income settings.

The hypotheses of the study as stated in the null are as follows; a) There is no impact of price, product, promotion, place, and Perception on community pharmacists (CPs) involvement with existing supply channels in Nigeria, and, b) There is no dominant marketing-mix variable of operational importance to the study of Community pharmacists' engagement with supply channels

\section{MATERIALS AND METHODS}

\section{Ethical approval}

Ethical approval with approval number HPRS/381/371 dated $10^{\text {th }}$ May 2021 from the Department of Health Planning, Research and Statistics, Ministry of Health, Ogun State, Nigeria. Informed oral consent was obtained from respondents before the administration of the research instrument

\section{Study design}

A cross-sectional study which used a descriptive-analytical technique with literature-guided questionnaires administered to community pharmacists in selected cities in South West, Nigeria

\section{Study setting and area}

The study took place in Lagos, Ogun, and Oyo states. They are the 3 most populous states in the South Western part of Nigeria, with a population of over 21 million people, according to the data from the National Bureau of Statistics $[18,19]$. The study frame consisted of all community pharmacists in Lagos, Ogun, and Oyo states. They have a total of about 1,800 community pharmacists.

\section{Questionnaire design}

A structured questionnaire was developed based on a comprehensive literature review and from the opinions of experts in the field. The questionnaire is composed of two parts, namely. The first part consists of socio-demographic variables. The second part consists of 26-item Likert scale questions classified based on literature-guided information into Price, Promotion, Place, Product, and Perception sub-headings or categories. The 5-point Likert scale options ranged from 1 to 5 where strongly agree (5), agree (4), undecided (3), disagree (2), and strongly disagree (1).

\section{Eligibility criteria}

Community pharmacists and/or pharmacist managers with procurement roles were included in the study. The rationale for this is to ensure that only pharmacists with relevant experience on procurement issues are recruited.

\section{Exclusion criteria}

Non-pharmacists and non-pharmacist managers were not included in the study. Pharmacists with no supervisory or oversight responsibility or involvement with drug procurement were also excluded.

\section{Sample size}

Raosoft sample size calculator was used to obtain a computed sample of 317 from a population of 1,800 community pharmacists in Lagos, Ogun, and Oyo states. A 5\% margin of error and 95\% confidence for sample size determination [20]. However, a total of 398 respondents were obtained for the study.

\section{Sampling technique and data collection}

A mixed sampling method was adopted for the administration of the questionnaires in the study. Firstly, judgmental sampling was used to select community pharmacists with procurement roles. Thereafter, the Random sampling method was used to obtain respondents. This was done to minimize researcher bias in judgmental sampling

\section{Internal validity of research instrument}

The internal validity of the instrument was 0.78 Cronbach alpha coefficient. Face validity was achieved by an expert group of community pharmacists and academics

\section{Item definition, classification, and processing}

As shown in table 1 below, the Likert scale questions were applied to 26 -item questions to elicit responses from respondents as to their level of involvement with supply channels. The 26-items were categorized into 5 groups (Price, Place, Promotion, Product, and Perception) using the attributes inherent in the marketing-mix characteristics.

\section{Measurements of response and impact scale/s}

The 5-point Likert scale ranged from 1 (strongly disagree) to 5 (strongly agree). To compute the range of responses, the difference in the value of the maximum and minimum was calculated $(5-1=4)$ to give the class width. Data range was obtained by dividing the class width by the number of responses $(4 / 5=0.8)$. This provided the range of scores to measure impact level as shown in table 1 below [21-23].

Table 1: Measures of impact scale for the study

\begin{tabular}{llll}
\hline Likert scale & Response & Threshold range & \\
\hline 1 & strongly disagree & $1.00-1.80$ & Impact level \\
2 & disagree & $1.81-2.60$ & Very Low (VL) \\
3 & neutral & $2.61-3.40$ & Low (L) \\
4 & agree & $3.41-4.20$ & Moderate (M) \\
5 & strongly agree & $4.21-5.00$ & High (H) \\
\hline
\end{tabular}

\section{Development of mean scores}

The mean scores of responses to the Likert scale questions were computed from each respondent's answers to questions relating to purchasing engagements with three main supply channels in Nigeria, namely. Pharmaceutical companies, local wholesaler channels, and Mega Distributors in open-drug market channels. The mean scores were used for analysis. Mean scores for marketing-mix variables were made from the mean of item variables representing each marketing variable. Hence, 'Product' variable was obtained from the mean of response to items 1 to 7 ; 'Price' from items 8 to 15; 'Place' from items 16 and 17; 'Promotion' from items 18 to 21; and 'Perception' from items 22 to 26 .

\section{Data analysis}

Descriptive statistics such as mean, standard deviation, and median and inferential statistical measures such as the Chi-square test were used to 
test the significance of the association between categorical variables. Ttest was used to test the statistical difference in means between groups.

\section{RESULTS}

\section{Response rates and demographic statistics}

A total of 398 were valid out of 500 questionnaires randomly administered to purposively selected community pharmacists (CPs) in Lagos, Oyo, and Ogun states from March to May 2021. This represented a response rate of about $79.6 \%$, which was found to be sufficient for further statistical use. Demographic characteristics of respondents showed that 55\% (217) were male and 45\% (181) female. 79\% (314) have Bachelor of Pharmacy as first degree compared to $21 \%$ (84) who had Doctor of Pharmacy. 90\% (359) have no postgraduate degree, compared to $10 \%$ (39) who had postgraduate qualifications. Age-wise, 76.7\% (305) of respondents were between 20 to 40 y compared to 93 (23.3\%) who were above $41 \mathrm{y}$. The business model operated by CPs was 60\% (238) core retail, $15 \%$ (59) wholesale, and 25\% (101) operated mixed model. Type of owner showed that 54\% (213) were sole owners, 16\% (62) partnership, and 30\% (123) were pharmacist-managers. Years of experience as a pharmacist showed $40 \%$ (158) within 1 to $5 \mathrm{y}, 34 \%$ (136) between 6 to $10 \mathrm{y}$, while $26 \%$ (104) between 11 to above $20 \mathrm{y}$. Employee number count revealed the majority 57\% (227) had 1 to 5 persons, $30 \%$ (120) had 6 to 10 persons, while a cumulative $12.8 \%$ (51) had between 11 to over 20 employees. In terms of location, $55 \%$ (218) respondents in Urban, 32\% (127) in Suburban, and 13\% (53) in rural respondents.

Table 2: Test of association between demographic attributes of community pharmacists and marketing mix variables

\begin{tabular}{|c|c|c|c|c|c|c|}
\hline \multirow{2}{*}{$\begin{array}{l}\text { Variables } \\
\text { Demographics }\end{array}$} & \multirow{2}{*}{$\begin{array}{l}X^{2} \\
p \text {-value }\end{array}$} & \multicolumn{5}{|c|}{ Marketing marketing-mix variables } \\
\hline & & Price & Product & Place & Promotion & Perception \\
\hline Age & 0.05 & $* * 0.00$ & 0.09 & 0.20 & 0.09 & 0.15 \\
\hline Gender & 0.05 & 0.72 & 0.24 & 0.60 & 0.30 & 0.15 \\
\hline Type of Ownership & 0.05 & 0.54 & 0.76 & $* 0.03$ & 0.62 & 0.15 \\
\hline Years of Managerial experience & 0.05 & $* 0.01$ & 0.38 & 0.61 & 0.25 & 0.70 \\
\hline Years of experience as pharmacist & 0.05 & 0.10 & 0.84 & 0.91 & 0.37 & 0.21 \\
\hline Business model & 0.05 & 0.67 & 0.08 & 0.07 & 0.11 & 0.07 \\
\hline Location of Business premise & 0.05 & 0.61 & 0.78 & 0.14 & 0.28 & $* 0.05$ \\
\hline Number of employees & 0.05 & $* * 0.00$ & 0.38 & $* 0.02$ & 0.11 & 0.60 \\
\hline State of Operation & 0.05 & 0.07 & 0.74 & 0.18 & 0.34 & 0.11 \\
\hline
\end{tabular}

Note: $\mathrm{p}$-value significant at $<0.05,{ }^{*} \mathrm{p}<0.05,{ }^{* *} \mathrm{p}<0.01,95 \%$ Confidence Interval

Table 3: Evaluation of variables involved in community pharmacists' engagement with supply channels

\begin{tabular}{|c|c|c|c|c|c|c|c|}
\hline Study variables & Mean & SD & Impact level & Ranking & t-value & p-value & Inference \\
\hline Product & 2.46 & 0.41 & & & & & \\
\hline \multicolumn{8}{|l|}{ Items } \\
\hline 1. Product variety & 2.41 & 0.64 & low & 5 & 1.312 & 0.189 & not significant \\
\hline 2. purchase mostly non-prescription drugs & 2.5 & 0.71 & low & 3 & 0.973 & 0.331 & not significant \\
\hline 3. purchase mostly prescription-only drugs & 2.45 & 0.67 & low & 4 & 1.016 & 0.31 & not significant \\
\hline 4. Provision for return/replacement of defective products & 2.51 & 0.65 & low & 2 & 1.298 & 0.195 & not significant \\
\hline 5. Assured product quality and source & 2.4 & 0.61 & low & 6 & 0.271 & 0.786 & not significant \\
\hline $\begin{array}{l}\text { 6. purchase both non-prescription and prescription-only } \\
\text { medicines }\end{array}$ & 2.3 & 0.66 & low & 7 & 2.824 & **0.005 & significant \\
\hline 7. Product information from supplier & 2.61 & 0.61 & moderate & 1 & 5.429 & ${ }^{* *} 0.000$ & significant \\
\hline PRICE & 2.65 & 0.34 & & & & & \\
\hline \multicolumn{8}{|l|}{ Items } \\
\hline 8. Get better product pricing & 2.38 & 0.58 & low & 8 & 8.012 & ${ }^{* *} 0.000$ & significant \\
\hline 9. Spend less on transportation costs & 2.52 & 0.58 & low & 5 & 3.858 & ${ }^{* *} 0.000$ & significant \\
\hline 10. Negative impact on profit margins & 3.18 & 0.85 & moderate & 1 & 11.55 & ${ }^{* *} 0.000$ & significant \\
\hline 11. Opportunity to negotiate pricing & 2.61 & 0.6 & moderate & 3 & 1.157 & 0.248 & not significant \\
\hline 12. Increased cost of doing business & 2.94 & 0.7 & moderate & 2 & 7.434 & ${ }^{* *} 0.000$ & significant \\
\hline 13. Regular Updates on price changes & 2.52 & 0.6 & low & 6 & 3.761 & ${ }^{* *} 0.000$ & significant \\
\hline 14. Access to credit facility & 2.6 & 0.63 & low & 4 & 1.393 & 0.164 & not significant \\
\hline 15. More profit-making opportunity from the channel & 2.44 & 0.6 & low & 7 & 6.075 & ${ }^{* *} 0.000$ & significant \\
\hline PLACE & 2.61 & 0.51 & & & & & \\
\hline \multicolumn{8}{|l|}{ Items } \\
\hline 16. Ease of access to supplier & 2.41 & 0.64 & low & 2 & 4.876 & ${ }^{* *} 0.000$ & significant \\
\hline 17. Proximity to Business Premise & 2.8 & 0.69 & moderate & 1 & 4.418 & ${ }^{* *} 0.000$ & significant \\
\hline PROMOTION & 2.73 & 0.43 & & & & & \\
\hline \multicolumn{8}{|l|}{ Items } \\
\hline 18. Enjoy promos on volumes purchased & 2.58 & 0.62 & low & 3 & 3.966 & ${ }^{* *} 0.000$ & significant \\
\hline 19. Buy large volumes as a result of their activities & 2.55 & 0.62 & low & 4 & 4.759 & ${ }^{* *} 0.000$ & significant \\
\hline 20. Buy small quantities as a result of their activities & 2.76 & 0.7 & moderate & 2 & 0.729 & 0.466 & not significant \\
\hline $\begin{array}{l}\text { 21. Have Contractual Business agreements with the } \\
\text { supplier }\end{array}$ & 3.03 & 0.9 & moderate & 1 & 6.000 & ${ }^{* *} 0.000$ & significant \\
\hline PERCEPTION & 2.48 & 0.42 & & & & & \\
\hline \multicolumn{8}{|l|}{ Items } \\
\hline 22. Enjoy the seamless business flow & 2.21 & 0.58 & low & 5 & 7.522 & ${ }^{* *} 0.000$ & significant \\
\hline 23. Enable meeting Customers' needs promptly & 2.37 & 0.65 & low & 4 & 2.836 & ${ }^{* *} 0.005$ & significant \\
\hline 24. Improves administrative time for other activities & 2.55 & 0.62 & low & 2 & 1.865 & 0.063 & not significant \\
\hline 25. Enjoy satisfactory service from supplier & 2.43 & 0.61 & low & 3 & 1.347 & 0.178 & not significant \\
\hline $\begin{array}{l}\text { 26. Experienced improved Business activity due to COVID } \\
\text { in the past year }\end{array}$ & 2.74 & 0.41 & moderate & 1 & 8.837 & ${ }^{* *} 0.000$ & significant \\
\hline
\end{tabular}

Note: p-value significant at $<0.05,{ }^{*} \mathrm{p}<0.05,{ }^{* *} \mathrm{p}<0.01,95 \%$ Confidence Interval, $\mathrm{SD}=$ standard deviation 
Table 2 showed that demographic variables of age, type of ownership, number of employees, years of managerial experience were significantly associated with marketing-mix variables such as Price (Age, number of employees, managerial experience), Place (type of ownership, number of employees), Perception (location of business premise). However, Product and Product did not show any significant association with any of the demographic attributes of Community pharmacists. The association of Age will price component had the highest significance $(p<0.001)$ compared to the number of employees with Price $(\mathrm{p}=0.003)$.

Table 3 shows various items in each marketing-mix category and their respective Impact ratings. It also reveals the t-values obtained from comparing the means of each Marketing variable with that of each item in each category. Under the category Product, all items had 'low impact scores' below the threshold outlined in table 1 .
However, only the item "supply of product information" had a moderate impact level under the category.

However, under the Price category, moderate impact scores were obtained from items 'negative impact on margins', 'opportunity to negotiate prices' and 'Increase the cost of doing business Similarly, under the Promotion category, items "buy small quantities as a result of promo activities' and 'have contractual business agreements with supplier' both had moderate impact scores compared to other items. Perception category had only one moderate impact level item 'experienced improved business due to COVID in the past $12 \mathrm{mo}$.

Table 4 provides a summary of the Marketing-mix variables and their mean score, impact level, and ranking. 'Promotion' had the highest-ranking with moderate impact, followed by Price with moderate impact, Place with moderate impact, Perception with low impact, and lastly, Product with low impact.

Table 4: Impact of marketing-mix variables on community pharmacists' engagement and hypothesis testing

\begin{tabular}{llllll}
\hline Marketing-mix variables & Mean & SD & Impact level & Ranking & Inference \{Hypothesis) \\
\hline Product & 2.46 & 0.41 & low & 5 & Low impact on CPs' decision \\
Price & 2.65 & 0.34 & moderate & 2 & Moderate impact on decision-making \\
Place & 2.61 & 0.51 & moderate & 3 & Moderate impact on decision \\
Promotion & 2.73 & 0.43 & moderate & 4 & Moderate impact on decision \\
Perception & 2.48 & 0.42 & low & Low impact on CPs' decision & Reject null hypothesis \\
Overall value & 2.59 & 0.42 & low-moderate & not applicable & \\
\hline
\end{tabular}

$\mathrm{SD}=$ standard deviation, *Promotion is the most dominant marketing-mix variable

\section{DISCUSSION}

The uniqueness of this study is that it shifts the mirror of analysis from the perspective of suppliers to those at the retail end of the value chain, (the CPs), as to how they engage marketing-mix principles to inform their procurement decisions. There were several limitations to the study. Firstly, the study was carried out in the southwest region of Nigeria and hence, the generalizability of the result is therefore limited. The marketing-mix attributes in the questionnaire need to be expanded to include more factors to enhance study outcomes. The outcomes of the study based on tables 3 and 4 were expounded as follows:

The impact of the 'product' on CPs procurement engagement with Supply channels revealed that overall involvement was low. The findings showed that the mean scores of product items revealed very low involvement in terms of engagement with the least rank apart from item 'product information obtained from suppliers' with a moderate score. This is particularly of considerable concern due to the near absence of quality checks on products before procuring, inadequate focus on the reliability of sourcing, whether from pharmaceutical companies, wholesalers, and mega distributors. This is because the issue of fake and counterfeit medicines is an ongoing challenge in developing countries, including Nigeria $[9,17]$.

The impact of 'price' on CPs procurement engagement with Supply channels showed that overall involvement was moderate. The study found out that profit-making from suppliers was least impactful compounded by high-cost transportation of goods from supplier to retailer, which may perhaps negatively influence returns on investment and product availability as a consequence $[7,15]$. This is probably linked to the limited access to credit facilities from suppliers.

The impact of 'promotion' on CPs procurement engagement with Supply channels showed that 'Promotion' had the most impact on CPs' engagement; which is indicative of the general focus of respondents. Promotion in the context of this study refers to the activities of suppliers towards increasing the level of awareness and patronage of their products. Although respondents mostly procured in small quantities compared to large quantities, contractual business arrangements with suppliers as a strategy to improve business volume were moderately adopted [16, 20, 25].

Furthermore, the impact of 'place' on CPs procurement engagement with Supply channels revealed the overall impact of Place was 'moderate'. In addition, the study showed that community pharmacists considered proximity to the business premise with suppliers as critical to their engagement, as confirmed by moderate scoring of its involvement. However, the ease of access to the supplier was scored low. This represents a gap that should be managed because timeliness and ease of access to where medicines can be procured are important. This is in harmony with one of the tenets of rational drug use, which expects medicines to be available on time $[13,14]$. However, proper inventory management at the community pharmacy level should be able to mitigate the likely negative effects of impaired access to suppliers.

The study revealed that the impact of 'perception' on CPs procurement engagement with Supply channels had overall low involvement. In this study, perception is viewed from the perspective of the community pharmacist as per how CPs perceived overall value from suppliers and other related factors. Findings showed that business flow, ability to cater to patients' needs, administrative time savings, level of satisfaction with suppliers' services were all below expectation (low impact). This calls for more attention from supply chain managers involved in the supply of medicines to community pharmacies to proffer more efficient ways to ensure the availability of products and services to their clients. In contrast, respondents had a moderate level of response as to improved profitability in the last 12 mo. This spike in sales and profitability is not unrelated to an astronomical increase in the demand for medicines and healthcare products during the COVID-19 lockdown period $[24,25]$

Finally, the overall impact of Marketing-mix variables on CPs procurement engagement with supply channels based on the findings of this study was evaluated [Table 4]. Aggregate impact was considered 'low-moderate" as shown by a mean score of 2.59 which is below 3.41 baseline for high impact. This implies that the level of involvement by CPs in activities and decisions involving MARKETING-MIX: product, price, promotion, place, and their perception of value has to be improved. This is very important in healthcare practice settings in low and middleincome countries. The findings of this study showed that 'Promotion' had the most significant impact on the engagement of CPs in the supply channel. This finding is supported by Thabit and Raewf, 2018 [26]. The study provided a framework to support balanced engagement between community pharmacists and their suppliers. 
The study hypotheses were therefore tested based on the outcomes of the study, the null hypothesis that there is no impact of marketing mix on CPs; engagement with supply channels was rejected because there was the low-moderate impact of marketing mix variables in CPs engagement. Also, the null hypothesis that there is no dominating marketing mix variable was rejected as the Product variable was the most dominant. This finding is supported by a study that examined the place of generic products in delivering affordable healthcare in developing countries [27].

Based on the study outcomes, there are implications for community pharmacy practice in low and middle-income countries where access to safe and affordable medicines is an essential indicator of qualitative healthcare delivery. It is essential for CPs to adopt a balanced blend of marketing-mix practices to ensure quality, pricefriendly, accessible, and service-driven pharmaceutical care delivery. In addition, the Implications for policymakers is that it is imperative to adopt and adapt Marketing-mix concepts (Product, Price, Place, Promotion, and Perception) towards optimizing the relationship between healthcare providers and supply channels of medicines. Healthcare providers can improve the quality of procurement decisions with the optimal application of marketing-mix concepts. The study provides a framework to support balanced engagement between community pharmacists and their suppliers. Improved focus on key priorities that can positively impact the delivery of pharmaceutical care to the patient.

\section{CONCLUSION}

The role of the marketing mix in healthcare cannot be overemphasized. Community pharmacists as frontline medication experts need to apply the principles of price, place, product, product, and perception, in informing their procurement activities. There is an apparent shift of priority focus from product-based attributes, to more of price-sensitivity, stock availability and access. The study recommends a more balanced approach to be adopted among healthcare managers when making procurement decisions.

\section{LIMITATIONS OF THE STUDY}

There are several limitations of the study, firstly, the research study was conducted in the Southwestern part of Nigeria and hence there is the limitation of generalizability to other geographical regions of the country. Secondly, there is the need to expand/increase the number of attributes constituting each marketing mix concept.

\section{ACKNOWLEDGMENT}

Authors wish to appreciate the management of Ogun State Ministry of Health Research and Statistics department for their approval of this research work.

\section{FUNDING}

Nil

\section{AUTHORS CONTRIBUTIONS}

Oamen Theophilus was responsible for conceptualization, questionnaire development, data collection, and data analysis. Oamen S Omorenuwa was responsible for data review, and proofreading of the manuscript.

\section{CONFLICT OF INTERESTS}

\section{Declared none}

\section{REFERENCES}

1. Taylor S, Cairns A, Glass B. Expanded practice in rural community pharmacy in Australia: pharmacists' perspectives. J Pharm Pract Res. 2021;51(1):43-53. doi: 10.1002/jppr.1688.

2. Hepler CD, Strand LM. Opportunities and responsibilities in pharmaceutical care. Am J Hosp Pharm. 1990;47(3):533-43. doi: 10.1093/ajhp/47.3.533, PMID 2316538.

3. Festa G, Cuomo MT, Metallo G, Festa A. The (r)evolution of wine marketing mix: from the 4Ps to the 4Es J Bus Res. 2016;69(5):1550-5. doi: 10.1016/j.jbusres.2015.10.015.

4. Al Badi KS. The impact of marketing mix on the competitive advantage of the SME sector in the al buraimi governorate in oman. SAGE Open. 2018;8(3):1-10. doi: 10.1177/2158244018800838.
5. Mei LS. Marketing Mix (7P's) and performance assessment of Western fast-food Industry in Taiwan: an application by associating DEMATEL and ANP. Afr J Bus Manag. 2011;5(26);10:10644-834.

6. Bahman SP, Kamran N, Mostafa E. The effect of the marketing mix in attracting customers: case study of Saderat Bank in Kermanshah Province. Afr J Bus Manage. 2013;7(34):3272-80. Doi. doi: 10.5897/AJBM12.127.

7. Singh M. Marketing mix of $4 \mathrm{P}^{\prime} \mathrm{s}$ for competitive advantage. IOSRJBM. 2012;3(6):40-5. doi: 10.9790/487X-0364045.

8. Avlonitis GJ, Indounas KA. Pricing objectives and pricing methods in the services sector. J Serv Mark. 2005;19(1):47-57. doi: 10.1108/08876040510579398.

9. Aigbavboa S, Mbohwa C. The headache of medicines supply in Nigeria; an exploratory study on the most critical challenges of the pharmaceutical outbound value chain. Proceedings of the Manuf; 2020. p. 336-43.

10. Ogbonna BO. National drug distribution in Nigeria; Implications for the goals of national drug policy. Eur J Pharm Res. 2016;3(1):1-4.

11. Oliveira MG, Toaldo AN. New times, new strategies; proposal for an additional dimension to the 4P's for e-commerce DOT. COM. J Inform Syst Tech Manage. 2015;12:107-24. doi: 10.4301/S180717752015000100006.

12. Mathieu V. Product services: from a service supporting the product to a service supporting the client. J Bus Ind Mark. 2001;16(1):39-61. doi: 10.1108/08858620110364873.

13. Goi CL. A Review of Marketing Mix: 4Ps or More? Int J Mark Stud. 2009;1(1):2-15. doi: 10.5539/ijms.v1n1p2.

14. Thabit TH, Younus SQ. The relationship between added-value of organization and QMA. Int J Soc Sci Educ Stud. 2015;4(4):100-9.

15. Ushie BA, Ugal DB, Ingwu JA. Overdependence on for-profit pharmacies: a descriptive survey of user evaluation of medicines available in public hospitals in selected Nigerian States. Plos One. 2016;11(11):e0165707. doi: 10.1371/journal.pone.0165707. PMID 27812177.

16. Latif A, Abideen ZU. Effects of television advertising on children; A Pakistani Perspective. Eur J Econ Fin Admin Serv. 2011;30(4):38-49.

17. Akiny O. Counterfeit drugs in Nigeria: a threat to Public Health. Afr J Pharm Pharmacol. 2013;7(36):2571-6. doi: 10.5897/AJPP12.343.

18. Pharmacists Council of Nigeria. List of Registered Community Pharmacies in Nigeria. Available from: https;//www.pcn.gov.ng [Last accessed on 10 Feb 2021]

19. National Bureau of Statistics. 2017 demographic statistics bulletin. Available from: http;//nigerianstat;2018.gov.ng. [Last accessed on 10 Apr 2021]

20. Sample size calculator [online]. Available from; http;//www.raosft.com/samplesize,html2016;2016.com. [[Last accessed on 10 Dec 2020]

21. Kassem MA, Khoiry MA, Hamzah N. Using relative importance index method for developing risk map in oil and gas construction projects. J Kejuruteraan. 2020;32(3):85-97. Doi.10.17576/jkukm-2020-32(3)-09.

22. Tamtekin, Bayer. The impact of different demographic variables on determinants of university choice decision: a study on business administration students of the foundation universities in istanbul. Theor Pract. 2016;16:1147-69. doi: 10.12738/estp.2016.4.0195.

23. Kan A. Measurement results on the statistical. Measurement and evaluation in education. Ankara, Turkey; 2009. p. 397-456.

24. Renganathan R, Vijayabanu C, Srinivasakumar V, Vijay AV. Pharmaceutical pricing and control: Indian perspective. Asian J Pharm Clin Res. 2016;9(6):305-8. doi: 10.22159/ajpcr.2016. v9i6.14461.

25. MV, GNKG. Pharmacy professions in India during covid-19 pandemic: present status, future challenges and a way forward. Int J Appl Pharm. 2021;13(1):32-5. doi: 10.22159/ ijap.2021v13i1.39688.

26. Thabit HT, Raewf MB. An evaluation of marketing mix elements; a case study. Int J Soc Sci Educ Stud. 2018;4(4):100-9.

27. Vignesh $\mathrm{M}$, Ganesh GNK. Generic prescriptions in India-A review. Asian J Pharm Clin Res. 2020;13(9):20-4. doi: 10.22159/ajpcr.2020. v13i9.38428. 